\title{
Avaliação do Impacto Social: um Levantamento Bibliométrico
}

\section{Social Impact Assessment: a Bibliometric Survey}

\author{
Emanuel Campigotto Sandri \\ Universidade Federal do Paraná - UFPR - Brasil \\ emanuel.sandri@hotmail.com \\ ORCID: 0000-0002-4539-2090 \\ Julia Mitsue Vieira Cruz Kumasaka \\ Universidade Federal do Paraná - UFPR - Brasil \\ juliamitsue@hotmail.com \\ ORCID: 0000-0002-2148-7140 \\ June Alisson Westarb Cruz \\ Pontifícia Universidade Católica do Paraná - PUCPR - Brasil \\ june.cruz@pucpr.br \\ ORCID: 0000-0002-4183-9983 \\ Giovani Cruzara \\ Universidade Federal do Paraná - UFPR - Brasil \\ giovani.cruzara@outlook.com \\ ORCID: 0000-0001-5128-5948
}

Submetido em 18/05/2020; Aprovado em 16/08/2020.

\begin{abstract}
Resumo
Objetivo do estudo: apresentar o cenário científico sobre a avaliação do impacto social na área acadêmica da Administração e Negócios, tornando possível a criação de novos dados sobre o que está sendo pesquisado e quais as futuras direções da pesquisa em relação a indicadores de impacto social. Metodologia: foi utilizado como método o levantamento bibliométrico das publicações presentes na base de dados Web of Science, por meio das análises de citação, cocitação e bibliográficos. Posteriormente, esse método é combinado com uma revisão sistemática dos artigos presentes na área de Administração e Negócios. Principais resultados: a partir da abordagem bibliométrica, foi apresentado o número crescente de publicações, os principais autores sobre o tema em relação ao número de artigos e de citações, as universidades com mais estudos e as áreas de estudo com mais publicações sobre o tema. Já a revisão sistemática da área de administração demonstrou que a maior dificuldade dos estudos é entender como mensurar o impacto social, tendo o contexto papel importante para a mensuração dessa temática. Contribuições acadêmicas: foi possível mostrar, de forma ativa e objetiva, as principais conquistas do tema de pesquisa, bem como suas principais características e desafios futuros. Ademais, sobre os artigos da área de Administração e Negócios, foram indicadas, a partir de seus conteúdos, sugestões para estudos futuros, focando, principalmente, em mais exemplos práticos do que em discussões teóricas. Contribuições práticas: o presente estudo auxilia no entendimento sobre onde é necessário um maior desenvolvimento e atenção nas discussões sobre um tema tão relevante para diferentes atores da sociedade.

Palavras-chave: Impacto social. Avaliação de impacto. Bibliométrico. Revisão sistemática.
\end{abstract}

\section{Abstract}

Study objectives: in order to present the scientific scenario on the assessment of social impact in the academic area of administration and business, thus making it possible to create new data on what is being researched and what are the future directions of research in relation to social impact indicators. Methodology: it was used the bibliometric survey method of publications present in the Web of Science database, through citation, co-citation and bibliographic analyzes. Afterwards, this method is combined with a systematic review of literature of studies from administration and business area. Main results: the bibliometric results demonstrate an increase in the number of publications, the main authors on the 
subject in relation to the number of articles and citations, the universities with more studies, and the areas of study with more publications on the subject. While the systematic review demonstrated that the studies greatest challenge is to understand how to measure the social impact, with the context displaying an important role for the measurement of this theme. Academic contributions: it was possible to provide guidance, active and objective, regarding the main achievements of the research theme, as well as its main characteristics and future challenges. In addition, on the articles of administration and business area, suggestions for future studies were provided, focusing mainly on more practical examples than on theoretical discussions. Practical contributions: the present bibliometric review helps to understand where further development and attention is needed in discussions on such a relevant topic for different actors in society.

Keywords: Social impact. Impact assessment. Bibliometric. Systematic review.

\section{Introdução}

O debate sobre a importância e como fazer a avaliação do impacto social ocorre há tempos (Lovejoy, 1983; Milbrath et al., 1982), contudo continua sendo atual e crescentes as publicações acadêmicas nesse campo (Grieco, 2018; Polonsky et al., 2016).

Mesmo assim, bastante atenção é voltada para a busca de conceituações e justificativas (Antonie, 2012) e pouca para como realmente efetuar a avaliação do impacto social (Grieco, 2018). Assim, muitos continuam céticos sobre a possibilidade de realmente mensurar esse aspecto, considerando as ferramentas existentes incompletas diante da complexidade dos trabalhos com essa temática (Hervieux \& Voltan, 2019).

Nesse contexto, o presente artigo tem como objetivo central apresentar o cenário científico sobre a avaliação do impacto social na área acadêmica da Administração e Negócios, tornando possível a criação de novos dados sobre o que está sendo pesquisado e quais as futuras direções da pesquisa em relação a indicadores de impacto social.

Com tal abordagem, foi possível observar os aspectos mais frisados pelos autores na área de Administração e Negócios, como a dificuldade de se entender como mensurar o impacto social e a importância do contexto para as pesquisas, requisitando a adequação de instrumentos e de metodologias de acordo com o contexto e o tamanho dos projetos ou ações das organizações.

0 presente artigo apresenta-se estruturado em cinco seções afora esta introdução. Na segunda seção, tecem-se considerações sobre a avaliação do impacto social de acordo com a literatura utilizada. Na terceira seção, são descritos os procedimentos metodológicos abordados. Na quarta seção, são apresentados os resultados identificados e suas análises. Na quinta seção, discorre-se sobre as contribuições teóricas e práticas da pesquisa. E, por fim, na sexta seção, apresentam-se as considerações finais e as sugestões para pesquisas futuras.

\section{Revisão teórica}

0 presente item demonstra as principais abordagens teóricas acerca da temática da pesquisa, discorrendo sobre as principais formas de avaliação de impacto social, sua importância, e também as barreiras e dificuldades enfrentadas pelas organizações para conseguir realizá-la.

\subsection{0 que é impacto social}

O impacto social de uma organização é caracterizado pelas mudanças nas interações entre os diferentes atores de uma comunidade ou região, suas relações e suas ações, devido às atividades da organização. Para instituições que possuem um foco no desenvolvimento social, esse impacto é o alcance que seus produtos e serviços conseguiram ter, auxiliando a evolução da causa defendida (Hervieux \& Voltan, 2019).

Toda organização, de todos os setores e tamanhos, possui algum tipo de impacto social decorrente das suas atividades. Além disso, apresentam também o impacto ambiental e econômico, configurando sua responsabilidade no desenvolvimento sustentável da sociedade (Grieco, 2018).

Apesar de o conceito não ser complexo para o seu entendimento, ele pode ser considerado completamente ambíguo quando pensado no sentido prático. Ou seja, como realmente identificar o que é um impacto social (Cramer et al., 1980)?

De acordo com a Internacional Association for Impact Assessment (IAIA), instituição responsável internacionalmente por buscar boas práticas na medição dos impactos e auxiliar os gestores nas 
tomadas de decisões, a avaliação de impacto, de forma geral, significa o processo de buscar entender quais as possíveis consequências das atividades que estão sendo ou que pretendem ser realizadas (IAIA, 2020).

Assim, a avaliação do impacto social pode ser considerada o "processo de identificação das consequências futuras de uma ação atual ou proposta, relacionadas a indivíduos, organizações e macros sistemas sociais" (Becker, 2001, p. 312). Além disso, possui o objetivo de abordar aspectos importantes de uma sociedade, como a equidade e a justiça social (Leung et al., 2019).

Para Becker (2001), existem três tipos de avaliações de impacto social, sendo a primeira a que possui o foco no nível micro, que seria o impacto para os indivíduos. A segunda seria no nível "meso", que corresponderia às mudanças nas redes das organizações e das comunidades. E a terceira, estaria no nível macro que abarcaria os sistemas nacionais e internacionais. Logo, enquanto os dois primeiros níveis tratam mais dos aspectos locais, o último aborda mais os aspectos nacionais e internacionais. Esse é um dos motivos pelo qual Chavéz e Valenzuela (2019) apontam que é necessário considerar sabiamente o tamanho da escala do projeto ou da ação para definir a melhor forma de avaliar seus impactos.

Também é valido ressaltar a importância de se medir o impacto social direto e indireto, mesmo sendo complexo estabelecer as relações de causalidades, já que as áreas ou aspectos que possuem alguma influência pelas atividades das organizações são difusos, especialmente, quando se trata de impactos positivos (Chávez \& Valenzuela, 2019). 0 impacto social direto seria advindo propriamente das ações da organização, como suas emissões de gases poluentes ou suas ações de responsabilidade social corporativa. Já os impactos sociais indiretos são externalidades que ocorrem tendo alguma influência das atividades da organização, como o desenvolvimento da região onde essa está inserida, devido ao surgimento de outros comércios.

Apesar de as discussões sobre quais seriam as melhores metodologias para fazer essa mensuração, não existe um consenso. Mas boa parte dos autores concorda que devem ser usadas pesquisas com dados quantitativos e qualitativos, englobando, assim, aspectos subjetivos e objetivos, sem deixar que aspectos econômicos se sobressaiam aos impactos psicológicos (R. Antonie, 2012; Becker, 2001; Chávez \& Valenzuela, 2019; Hadad \& Gauca, 2014; Kunttu, 2017; Milbrath et al., 1982; Polonsky et al., 2016).

\subsection{Importância do impacto social}

Hadad e Gauca (2014) apontam que é notável que stakeholders valorizam mensurações. Isso ocorre, principalmente, quando estes são capazes de monitorar os prós e contras tangíveis e intangíveis, auxiliando nas tomadas de decisão (Kunttu, 2017) e na comparação e compreensão das organizações. Essa valorização da mensuração é ainda mais forte quando se trata de organizações ou atores financiadores, podendo esses ser públicos ou privados (Antonie, 2012).

Visto que as ações das organizações atingem as pessoas de formas e níveis diferentes, precisando existir uma contabilização disso (Mcinerney, 2017), quanto mais as empresas entenderem seus efeitos mais facilmente conseguirão maximizar seus benefícios sociais (Antonie, 2012). Entendendo seus impactos em determinada localidade ou em pessoas de forma geral, a empresa pode conseguir gerenciar melhor seus conflitos atuais com a comunidade ou prevenir a ocorrência de problemas futuros (Chávez \& Valenzuela, 2019). Com isso, pode-se também melhorar a imagem da organização quando se trata da sua responsabilidade social corporativa.

Além disso, organizações sem fins lucrativos necessitam dessas ferramentas para quantificar seu desempenho e conseguir atrair diferentes tipos de doadores, podendo por meio do impacto social, averiguar se sua missão está sendo cumprida (Grieco, 2018; Polonsky et al., 2016). Dessa forma, para muitas organizações a avaliação do impacto social já faz parte da formação de suas políticas (Becker, 2001). Porém, para algumas empresas ainda não existe uma total consciência dos benefícios gerados por essas medições e, por isso, muitas não realizam ou apenas o fazem por exigências externas (Grieco, 2018).

\subsection{Barreiras do impacto social}

A implementação da mensuração do impacto social tampouco está livre de barreiras. Para as organizações que entendem sua importância e desejam implementá-la, existem dificuldades que são encontradas para a sua elaboração e contínua avaliação.

Uma das mais observadas na literatura é a necessidade de recursos para a sua realização que engloba desde o tempo despendido até a falta de funcionários capacitados e habilidosos, principalmente, quando considerada a fase de coleta de dados, etapa em que são necessários dados internos e externos 
à organização. Por conta disso, nota-se, então, que seu custo dificilmente será baixo, fazendo com que a busca incessante por economias possa diminuir a eficiência da avaliação (Agarchand \& Laishram, 2017; Grieco, 2018; Mcinerney, 2017).

Ademais, parece existir a falta de uma visão de longo prazo, em se tratando de impactos futuros, ou seja, do valor social gerado e não de resultados imediatos e facilmente quantificáveis (Agarchand \& Laishram, 2017; Grieco, 2018; Hervieux \& Voltan, 2019; Polonsky et al., 2016). Dessa maneira, muitas organizações enfrentam a falta de informações específicas, sejam elas passadas, presentes ou futuras, além de dificuldades sistêmicas para obtê-las e armazená-las (Antonie, 2012; Mcinerney, 2017).

Além disso, organizações sem fins lucrativos apresentam uma falta de diálogo na difusão de melhores práticas no que se refere ao processo da avaliação do impacto social, o que faz com que exista a falta de uma orientação ou um exemplo a ser seguido (Grieco, 2018).

Ademais, a gerencia organizacional precisa ser envolvida e acreditar na sua importância, conseguindo, assim, passar motivação e comprometimento para os outros funcionários (Grieco, 2018). Porém, muitas vezes, esse entusiasmo já não é presente, visto que a organização só deseja cumprir o que é pedido por lei ou por existirem pensamentos internos conflitantes sobre a necessidade de realizar a avaliação (Mcinerney, 2017).

Para além desses aspectos operacionais, está a dificuldade de analisar o impacto social de forma sistêmica, entendendo as relações e conexões entre os atores envolvidos, suas ações, os processos e a dinâmica de poder presente (Hervieux \& Voltan, 2019).

\section{Método}

Esse artigo utiliza, em um primeiro momento, uma abordagem bibliométrica, para analisar as produções científicas da temática relacionada à avaliação do impacto social. Essa abordagem é então combinada com uma revisão sistemática para se analisar especificamente a área de Administração e Negócios, visando a identificar os avanços do tema no que diz respeito à avaliação do impacto social gerado por ações das organizações.

Levando em conta o método bibliométrico, esse procedimento possibilita a análise de bases de dados de produções científicas por meio de uma aproximação quantitativa, tornando possível analisar o campo temático de maneira sistêmica, e promover um mapeamento sobre a evolução do tema em estudo. Esse método utiliza técnicas como análise de citação, cocitação e acoplamento bibliográfico para aprimorar a análise quantitativa das coleções compostas por trabalhos acadêmicos (Osareh, 1996; Rocha et al, 2014).

Já o método de revisão sistemática é considerado por Liberati et al. (2009) como um método para se identificar e avaliar pesquisas relevantes, além de permitir coletar e analisar o que as pesquisas dizem por meio de seus dados. Com isso, o objetivo de uma revisão sistemática é identificar as evidências empíricas de estudos selecionados a partir de critérios de inclusão prévios, que tornam possível a identificação de respostas para as questões ou hipóteses de pesquisa (Snyder, 2019).

\subsection{Etapas operacionais da pesquisa bibliométrica}

Zupic and Čater (2015) apresentam cinco análises que podem ser realizas para demonstrar a relação entre os estudos, periódicos e palavras-chaves, sendo elas: a) análise de citação, b) análise de cocitação, c) bibliográficos, d) co-autoria, e) relação entre palavras-chave. Neste artigo, serão utilizadas as análises de citação, co-citação e bibliográficos, a partir do modelo sugerido por Zupic \& Čater (2015), o qual é apresentado de forma adaptada na

Tabela 1. Essa tabela contém os passos da metodologia de Zupic \& Čater (2015) e as atividades realizadas no presente estudo para cada passo do modelo.

A pergunta de pesquisa que norteou este artigo, correspondendo ao primeiro passo que foi: qual o panorama científico da temática de avaliação do impacto social? Nesse sentido, a definição de palavraschave começou com "Social Impact Assessment". Para identificar essa palavra-chave, foram realizadas buscas prévias no banco de dados da Web of Science, onde foram testadas as palavras-chave "social impact" and "indicator*" or "metric*". 0 resultado dessa pesquisa apresentou diversos artigos que demonstravam como o modelo de avaliação de impacto social se referia à temática pesquisada e como a incidência do termo "social impact assessment" era muito alta e com o conteúdo mais próximo do que se buscava com esse estudo. Assim, foi selecionado o termo "Social Impact Assessment" para compor a palavra-chave para esta pesquisa. 
Tabela 1 - Passos da Pesquisa Bibliométrica

\begin{tabular}{|c|c|c|c|c|c|}
\hline Passo & $\begin{array}{c}\text { Design da Pes- } \\
\text { quisa } \\
\end{array}$ & $\begin{array}{c}\begin{array}{c}\text { Compilação de Dados Bi- } \\
\text { bliométricos }\end{array} \\
\end{array}$ & Análise & Visualização & Interpretação \\
\hline \multirow{3}{*}{ 㘏 } & $\begin{array}{l}\text { Pergunta de pes- } \\
\text { quisa }\end{array}$ & $\begin{array}{l}\text { Pesquisa avançada sobre o } \\
\text { banco de dados Web of Sci- } \\
\text { ence }\end{array}$ & $\begin{array}{l}\text { Mineração dos da- } \\
\text { dos }\end{array}$ & $\begin{array}{l}\text { Desenvolvimento } \\
\text { de tabelas e gráficos } \\
\text { dos artigos }\end{array}$ & $\begin{array}{l}\text { Interpretação } \\
\text { dos resultados } \\
\text { encontrados }\end{array}$ \\
\hline & $\begin{array}{l}\text { Escolha do método } \\
\text { bibliográfico mais } \\
\text { adequado de } \\
\text { acordo com a ques- } \\
\text { tão da pesquisa }\end{array}$ & $\begin{array}{l}\text { Elaboração e compilação } \\
\text { de arquivos de bancos de } \\
\text { dados Web of Science }\end{array}$ & $\begin{array}{l}\text { Geração de } \\
\text { resultados no } \\
\text { pacote } \\
\text { Bibliometrix }{ }^{\circledR}\end{array}$ & $\begin{array}{l}\text { Escolha do software } \\
\text { mais adequado para } \\
\text { a visualização de } \\
\text { mapas } \\
\text { bibliométricos }\end{array}$ & $\begin{array}{l}\text { Contraposição } \\
\text { dos resultados } \\
\text { com a } \\
\text { literatura }\end{array}$ \\
\hline & $\begin{array}{l}\text { Definição de } \\
\text { palavras-chave }\end{array}$ & $\begin{array}{l}\text { Filtragem e exportação dos } \\
\text { dados bibliográficos } \\
\text { utilizando o pacote } \\
\text { Bibliometrix } ® \text { do software } \\
\text { estatístico R }\end{array}$ & $\begin{array}{l}\text { Seleção de dados e } \\
\text { gráficos }\end{array}$ & $\begin{array}{l}\text { Geração das } \\
\text { estatísticas no sof- } \\
\text { tware } \\
\text { Bibliometrix } ®\end{array}$ & $\begin{array}{l}\text { Síntese e } \\
\text { discussão }\end{array}$ \\
\hline
\end{tabular}

Fonte: Adaptado de Zupic e Čater (2015).

No segundo passo, que se refere à compilação de dados bibliométricos, a busca por artigos no banco de dados Web of Science foi realizada entre 28/12/2019 e 04/01/2020, sendo utilizada a palavrachave "Social Impact Assessment" nos campos título, resumo e palavras-chave ("Tópicos"). Na sequência, após a leitura do resumo dos artigos científicos, os selecionados foram exportados com extensão "BIB". Tais arquivos foram utilizados para as posteriores análises. Os arquivos ".BIB" contemplavam as informações sobre os autores, periódicos, títulos e palavras-chave, além de todas as referências usadas no estudo, para tornar possível a mensuração das citações abordadas nesses trabalhos.

0 número inicial de documentos encontrados ao buscar o termo "Social impact assesment" na base de dados utilizada foi de 544. Ao se aplicar o filtro para encontrar apenas artigos, esse número foi reduzido para 395. Os resumos desses 395 artigos foram lidos e identificaram-se 363 artigos que se encaixavam no foco do estudo de acordo com o seu conteúdo. Sobre esses 363 artigos, foram aplicadas as análises bibliométricas, contemplando todas as áreas disponíveis na Web of Science.

Para a análise, foi utilizado o software estatístico R em conjunto com o pacote de expansão bibliometrix (http://www.bibliometrix.org) (Aria \& Cuccurullo, 2017), especializado para analises bibliométricas. Após esse procedimento, foi iniciado o quarto passo, segmentado em duas etapas: geração dos dados (bibliometrix) e preparação da mensuração dos resultados.

Os dados gerados pelo software bibliometrix (R) foram armazenados e segmentados em categorias, como: a) autores mais citados, b) produções cientificas por países e centros de pesquisas.

Posteriormente, e a fim de realizar uma comparação do panorama geral com a área de Administração e Negócios, foi aplicado um filtro de restrição sobre essa área. Tal procedimento resultou na queda de 363 para 20 artigos.

Diante disso, e levando em conta que uma análise bibliométrica com tal quantidade seria inviável, foi optado por se realizar uma revisão sistemática desses artigos, usando uma abordagem qualitativa para complementar a metodologia quantitativa bibliométrica e tornar possível a compreensão do panorama do tema "avaliação do impacto social na área de Administração e Negócios".

A análise da área de Administração e Negócios foi escolhida pela contribuição ao entendimento dos impactos e, principalmente, pelo fato de investigar como a empresa pode gerenciar melhor seus conflitos ou prevenir a ocorrência de problemas futuros (Chávez \& Valenzuela, 2019). Como já apontado por Antonie (2012), um maior conhecimento por parte das empresas, no que diz respeito ao impacto social, pode contribuir para a maximização dos seus benefícios sociais. Os detalhes do procedimento de revisão sistemática são apresentados a seguir.

\subsection{Etapas operacionais da revisão sistemática}

Dos 20 artigos identificados na área de Administração e Negócios, foi verificado que um não era possível de ser acessado. Logo, os 19 restantes foram lidos inteiramente e analisados de acordo com o seu conteúdo, seguindo as recomendações de Snyder (2019). Para tanto, foram seguidos os quatro passos sugeridos pela autora na construção de revisões de literatura. A Tabela 2 sumariza os passos adotados para os procedimentos de revisão sistemática da pesquisa, contemplando também as atividades 
realizadas em cada passo.

Tabela 2 - Passos da Pesquisa da Revisão Sistemática

\begin{tabular}{|c|c|c|c|c|}
\hline Passo & $\begin{array}{l}\text { Design da } \\
\text { Pesquisa }\end{array}$ & Condução & Análise & $\begin{array}{l}\text { Estruturação e escrita } \\
\text { dos resultados }\end{array}$ \\
\hline \multirow{3}{*}{ 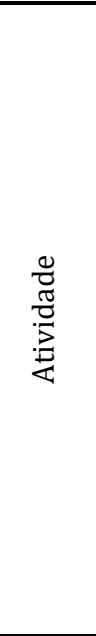 } & $\begin{array}{l}\text { Definição do } \\
\text { melhor } \\
\text { método para } \\
\text { revisão da li- } \\
\text { teratura }\end{array}$ & $\begin{array}{l}\text { Planejamento de } \\
\text { seleção de artigos }\end{array}$ & $\begin{array}{l}\text { Verificação da } \\
\text { abstração de in- } \\
\text { formações }\end{array}$ & $\begin{array}{l}\text { Fichamento dos artigos } \\
\text { selecionados }\end{array}$ \\
\hline & $\begin{array}{l}\text { Definição do } \\
\text { que a } \\
\text { pesquisa } \\
\text { procura } \\
\text { responder e } \\
\text { quais suas } \\
\text { potenciais } \\
\text { contribuições }\end{array}$ & $\begin{array}{l}\text { Documentação dos } \\
\text { procedimentos de } \\
\text { busca }\end{array}$ & $\begin{array}{l}\text { Geração de mapa } \\
\text { de colaboração } \\
\text { dos autores no } \\
\text { software } \\
\text { VOSViewer }\end{array}$ & $\begin{array}{l}\text { Explanação dos } \\
\text { resultados }\end{array}$ \\
\hline & $\begin{array}{l}\text { Definição de } \\
\text { palavras- } \\
\text { chave }\end{array}$ & $\begin{array}{l}\text { Validação e } \\
\text { detalhamento da } \\
\text { amostra de artigos } \\
\text { selecionados }\end{array}$ & $\begin{array}{l}\text { Identificação das } \\
\text { informações } \\
\text { mais relevantes } \\
\text { dos artigos }\end{array}$ & $\begin{array}{l}\text { Identificação e } \\
\text { exposição das } \\
\text { contribuições da pes- } \\
\text { quisa }\end{array}$ \\
\hline
\end{tabular}

Fonte: Adaptado de Snyder (2019).

Nota-se, com base na Tabela 2, que as atividades relacionadas aos passos design de pesquisa e condução são parecidos com as atividades realizadas na parte bibliométrica do trabalho, o que está correto, visto que a parte sistemática foi conduzida em uma amostra de artigos de uma área específica (Administração e Negócios), que também estava incluída na amostra maior utilizada para os procedimentos bibliométricos. Realizou-se, porém, uma adaptação da pergunta de pesquisa, visto que a revisão sistemática aborda apenas a área de Administração e Negócios. A pergunta de pesquisa foi adaptada da seguinte forma: qual o panorama científico da temática avaliação do impacto social na área de Administração e Negócios?

Maiores diferenças da Tabela 1 para a Tabela 2 aparecem nos últimos dois passos, pois a análise sistemática possui uma abordagem que tem o objetivo de sintetizar o estado da arte do conhecimento do campo e prover uma agenda para pesquisas futuras (Snyder, 2019).

Em complemento à revisão sistemática e buscando identificar os indicadores de cooperação entre autores, foi utilizado o software VOSviewer (van Eck \& Waltman, 2010) para se visualizar o mapa de cooperação entre os autores da área de Administração e Negócios.

Figura 1 - Número de documentos após cada filtro, com a indicação da utilização de cada metodologia usada

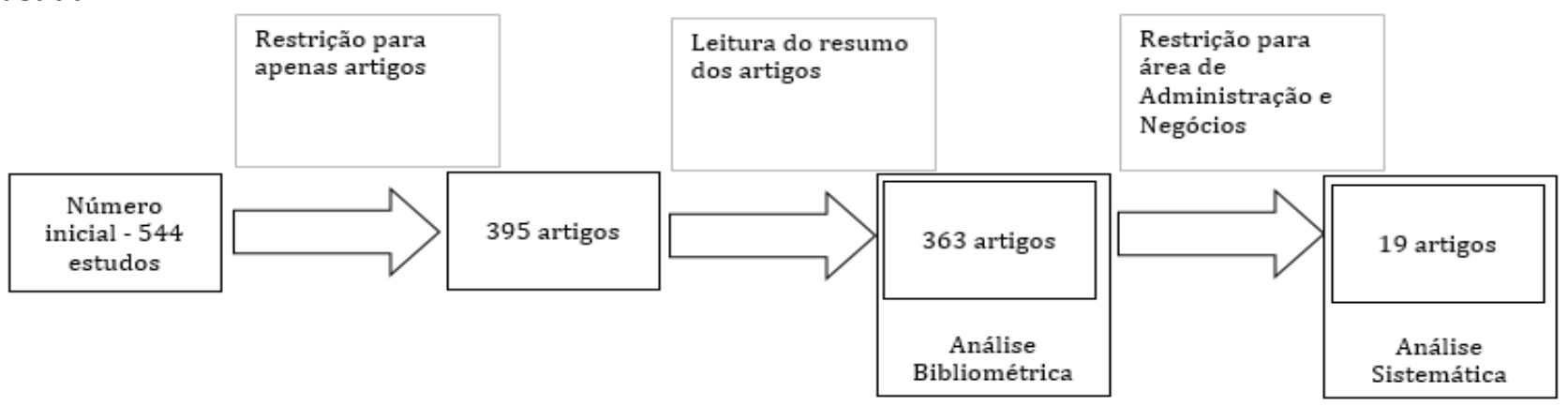

Fonte: Os autores (2020).

A figura 1 sumariza a junção das duas técnicas utilizadas (bibliométrica e revisão sistemática), demonstrando o número de artigos presentes em cada etapa da pesquisa.

\section{Resultados}

Estão sumarizados, nesta seção, os resultados provenientes das abordagens bibliométricas e sistemáticas. Inicia-se com a discussão dos achados bibliométricos do estudo, englobando, assim, todas as áreas de estudo nas quais foram identificados artigos. Posteriormente, apresentam-se as análises em 
relação ao conteúdo dos artigos da área de Administração e Negócios, o que contribui para uma visão sobre o estado atual do campo e para possíveis ideias para estudos futuros.

\subsection{Resultados bibliométricos}

Na busca do entendimento da evolução do campo de pesquisa da avaliação do impacto social, foram identificados os trabalhos acadêmicos dessa temática presentes no banco de dados da Web of Science.

Nota-se, em um primeiro momento, que dos 363 artigos identificados, 260 deles foram publicados no período de 2010 a 2019, com um aumento significativo no número de publicações nos últimos quatro anos. Na Figura 2, apresenta-se a evolução no número de publicações para o período de 2010 a 2019. Figura 2 - Evolução do número de publicações entre 2010-2019

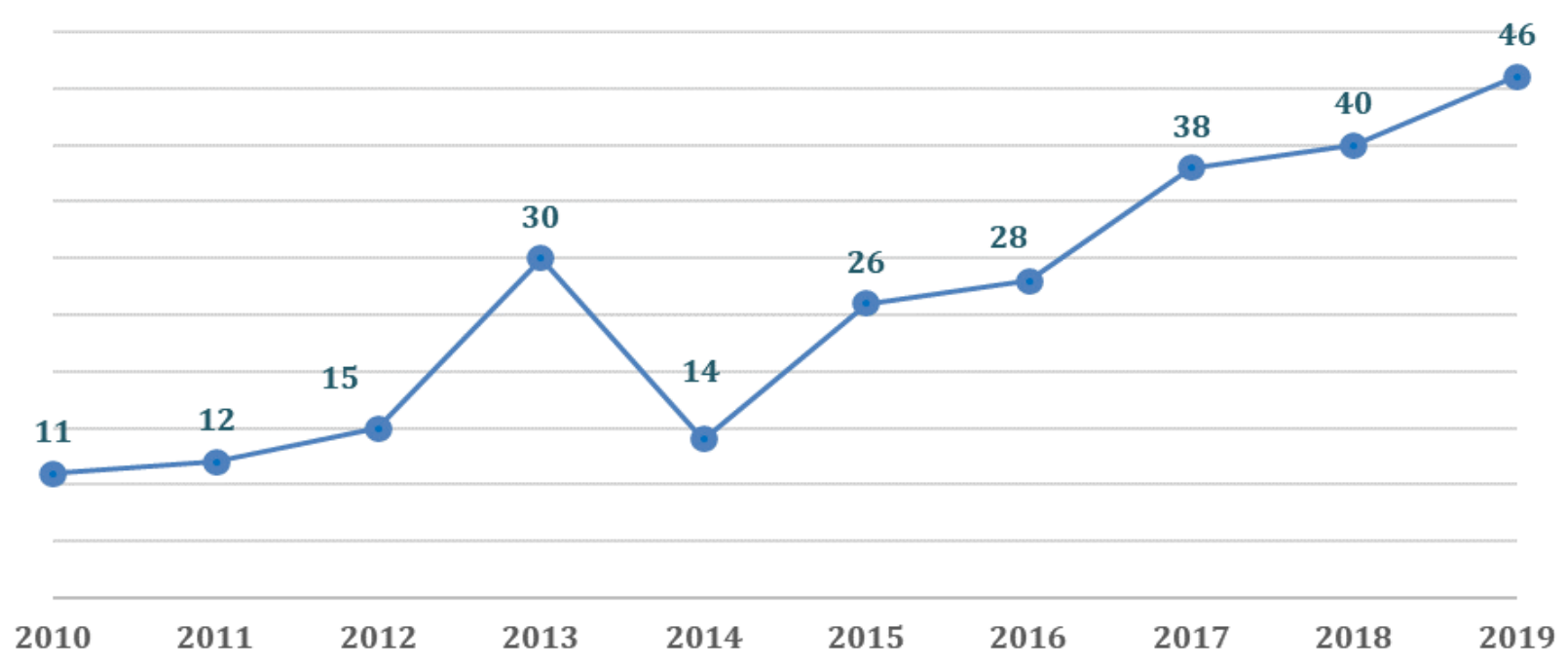

Fonte: Dados da pesquisa (2019).

Dando continuidade às análises, lista-se, na Dos dez periódicos exibidos na Tabela 3 foi identificado, por meio das informações de seus websites, que a grande maioria contempla aspectos que envolvem o meio ambiente. Isso demonstra que questões de impacto social aparentam estar diretamente relacionadas aos aspectos ambientas, ou ainda, que o campo ainda não atingiu sua maturidade, importando conteúdo e sendo ainda discutido em periódicos que tem como temas principais outras áreas. Isso porque notou-se que enquanto alguns periódicos aparentavam tratar especificamente de aspectos ambientais (Journal of Cleaner Production) ou de aspectos relacionados à sustentabilidade (Sustaintability), nenhum periódico apontou aspectos sociais como a área principal de escopo do periódico.

Tabela 3, o ranking dos dez periódicos com maior número de artigos científicos publicados. 0 periódico Environmental Impact Assessment Review figura no topo da lista, com aproximadamente 15\% de todos os artigos que compõem a amostra desse estudo.

Dos dez periódicos exibidos na Tabela 3 foi identificado, por meio das informações de seus websites, que a grande maioria contempla aspectos que envolvem o meio ambiente. Isso demonstra que questões de impacto social aparentam estar diretamente relacionadas aos aspectos ambientas, ou ainda, que o campo ainda não atingiu sua maturidade, importando conteúdo e sendo ainda discutido em periódicos que tem como temas principais outras áreas. Isso porque notou-se que enquanto alguns periódicos aparentavam tratar especificamente de aspectos ambientais (Journal of Cleaner Production) ou de aspectos relacionados à sustentabilidade (Sustaintability), nenhum periódico apontou aspectos sociais como a área principal de escopo do periódico.

Tabela 3 - Ranking dos dez periódicos com mais publicações de artigos

\begin{tabular}{clc}
\hline Ranking & \multicolumn{1}{c}{ Periódicos } & Artigos \\
\hline $1^{\underline{0}}$ & Environmental Impact Assessment Review & 53 \\
$2^{\underline{0}}$ & Impact Assessment and Project Appraisal & 42 \\
$3^{\circ}$ & International Journal of Life Cycle Assessment & 16 \\
$4^{\circ}$ & Journal of Cleaner Production & 13
\end{tabular}


Fonte: Os autores (2020).

Além disso, observa-se a predominância de periódicos dos Estados Unidos e Reino Unido, cada um com três periódicos listados na tabela. Esses são seguidos por periódicos de países europeus. Nenhum dos periódicos contidos na Tabela 3 é pertencente a um país em desenvolvimento ou que esteja fora da América do Norte ou Europa.

Para se verificar quais as universidades com mais trabalhos publicados, realizou-se a análise dos vínculos entre os autores dos trabalhos e as instituições das quais fazem parte. No que se refere às universidades que mais publicam, destaca-se a University of Groningen (Holanda), com 37 trabalhos publicados em periódicos, seguida das instituições University Of Queensland (Austrália) e Northwestern University (Estados Unidos), com 19 e 12 artigos, respectivamente.

Além disso, foi identificado quais autores mais publicaram sobre o tema na amostra coletada, com os resultados apresentados na Tabela 4, que, apesar de sugerir uma descentralização de pesquisas acadêmicas nessa temática entre países de referência na área, ainda assim, demonstra a concentração dessas pesquisas em países desenvolvidos, em especial, no eixo Europa-Estados Unidos.

Tabela 4 - Principais autores sobre Social Impact Assessment - SIA

\begin{tabular}{llcc}
\hline \multicolumn{1}{c}{ Autor } & \multicolumn{1}{c}{ Afiliação } & País da Instituição & Artigos \\
\hline Frank Vanclay & University of Groningen & Holanda & 37 \\
Ana Maria Esteves & University of Groningen & Holanda & 7 \\
Shobeir Karami & Shiraz University & Irã & 6 \\
Daniel Franks & University of Queensland & Austrália & 5 \\
William R. Freudenberg & University of Wisconsin & Estados Unidos & 5 \\
Jacki Schirmer & Australian National University & Austrália & 5 \\
\hline
\end{tabular}

Fonte: Os autores (2020).

Foi também verificado que os dois autores com maior número de publicações, o professor Dr. Frank Vanclay e a professora Dra. Ana Maria Esteves, ambos da University of Groningen - Holanda, são docentes e membros da consultoria internacional de gerenciamento de impacto social, conhecida como Community Insights Group - CIG. Em terceiro lugar, o professor Dr. Shobeir Karami (Shiraz University Irã) é um pesquisador que possui seis artigos científicos publicados na área. Tais dados denotam que, no aspecto geral do tema avaliação do impacto social, prevalece uma criação de material científico proveniente em grande parte de países desenvolvidos, com ênfase para o eixo América do Norte e Europa.

Na Tabela 5, são apresentados os trabalhos com mais citações, que sustentam ainda mais a proeminência da América do Norte e da Europa, visto que todos os artigos mais citados também são pertencentes a periódicos desse eixo.

Tabela 5 - Cinco documentos mais citados - Área Geral e Administração e Negócios

\begin{tabular}{|c|c|}
\hline ARTIGOS MAIS CITADOS - TODAS AS ÁREAS & $\begin{array}{l}\text { Número de Cita- } \\
\text { ções }\end{array}$ \\
\hline $\begin{array}{l}\text { Greider, T., \& Garkovich, L. (1994). Landscapes: The social construction of nature and the environ- } \\
\text { ment. Rural Sociology, 59(1), 1-24. }\end{array}$ & 395 \\
\hline $\begin{array}{l}\text { Kloepffer, W. (2008). Life cycle sustainability assessment of products. The International Journal of } \\
\text { Life Cycle Assessment, 13(2), } 89 .\end{array}$ & 339 \\
\hline $\begin{array}{l}\text { O'Faircheallaigh, C. (2010). Public participation and environmental impact assessment: Purposes, } \\
\text { implications, and lessons for public policy making. Environmental Impact Assessment Review, 30(1), } \\
\text { 19-27. }\end{array}$ & 235 \\
\hline $\begin{array}{l}\text { Esteves, A. M., Franks, D., \& Vanclay, F. (2012). Social impact assessment: the state of the art. Impact } \\
\text { Assessment and Project Appraisal, 30(1), 34-42. }\end{array}$ & 209 \\
\hline $\begin{array}{l}\text { Brouwer, R., \& Van Ek, R. (2004). Integrated ecological, economic and social impact } \\
\text { assessment of alternative flood control policies in the Netherlands. Ecological }\end{array}$ & 156 \\
\hline
\end{tabular}


Fonte: Os autores (2020).

A afirmação com relação a predominância de escopos que envolvem questões ambientais é também confirmada ao se analisar os dados contidos na Tabela 5, dado que todos os periódicos possuem relação direta de seu escopo com tais questões.

Os dados contidos na Tabela 6, que apresenta as dez principais áreas com mais publicações, também sustenta essa ênfase em periódicos da área ambiental, visto que as quatro primeiras áreas temáticas são diretamente relacionadas a questões ambientais, respondendo por mais de $80 \%$ do total de artigos da amostra.

Tabela 6 - Dez principais áreas temáticas de acordo com o número de documentos

\begin{tabular}{|c|c|c|}
\hline RANKING & ÁREA TEMÁTICA & ARTIGOS \\
\hline 10 & ESTUDOS AMBIENTAIS & 155 \\
\hline 2 o & CIÊNCIAS AMBIENTAIS & 75 \\
\hline $3^{\mathbf{o}}$ & ENGENHARIA AMBIENTAL & 36 \\
\hline 4⿻ & CIÊNCIA DA TECNOLOGIA VERDE SUSTENTÁVEL & 32 \\
\hline 5o & PLANEJAMENTO URBANO REGIONAL & 24 \\
\hline 6⿳⺈ & SOCIOLOGIA & 22 \\
\hline $7^{\mathbf{0}}$ & CIÊNCIAS SOCIAIS INTERDISCIPLINARES & 19 \\
\hline $8^{\circ}$ & ADMINISTRAÇÃO E NEGÓCIOS & 20 \\
\hline 9o & ESTUDOS DE DESENVOLVIMENTO & 17 \\
\hline 10 - & RECURSOS HÍDRICOS & 14 \\
\hline 110 & ANTROPOLOGIA & 11 \\
\hline $12 \mathbf{0}$ & ECOLOGIA & 11 \\
\hline $13^{\circ}$ & GEOGRAFIA & 11 \\
\hline $14^{\circ}$ & SAÚDE OCUPACIONAL PÚBLICA AMBIENTAL & 10 \\
\hline $15^{\circ}$ & ADMINISTRACC̃̃O PÚBLICA & 8 \\
\hline
\end{tabular}

Fonte: Os autores (2020).

Na tabela 6, em 8o lugar, contabilizando cerca de 5,5\%, encontra-se a área temática de Administração e Negócios. Tal área é explorada em maiores detalhes na seção seguinte, que contempla a etapa sistemática da pesquisa.

\subsection{Resultados da pesquisa sistemática}

A fim de explorar a área temática de Administração e Negócios, foi realizada a leitura e o fichamento dos 19 artigos presentes na Tabela 7. Neles, nota-se que existe, nos últimos anos, um pequeno aumento no número de artigos publicados. Porém, tal aumento ainda é pequeno e não pode ser considerado como um indicador que a área de Administração e Negócios está finalmente tendo maior atenção para o tema de avaliação do impacto social.

Tabela 7- Artigos analisados na área temática de Administração e Negócios

\begin{tabular}{|l|l|l|c|}
\hline \multicolumn{1}{|c|}{ Título } & \multicolumn{1}{c|}{ Autores } & \multicolumn{1}{c|}{ Periódico } & \multicolumn{1}{c|}{ Ano } \\
\hline $\begin{array}{l}\text { Measuring social impacts of energy projects at the small scale } \\
\text { level: methodological problems and policy implications }\end{array}$ & $\begin{array}{l}\text { Chávez; } \\
\text { Valenzuela }\end{array}$ & $\begin{array}{l}\text { Gestión y Política Pú- } \\
\text { blica }\end{array}$ & 2019 \\
\hline $\begin{array}{l}\text { Social impacts of work integration social enterprise in hong } \\
\text { kong - workfare and beyond }\end{array}$ & $\begin{array}{l}\text { Leung; Ho; Tjia; Tam; } \\
\text { Chan; Lai }\end{array}$ & $\begin{array}{l}\text { Journal of Social } \\
\text { Entrepreneurship }\end{array}$ & 2019 \\
\hline Toward a systems approach to social impact assessment & Hervieux; Voltan & $\begin{array}{l}\text { Social Enterprise Jour- } \\
\text { nal }\end{array}$ & 2019 \\
\hline $\begin{array}{l}\text { What do social entrepreneurs need to walk their talk? } \\
\text { Understanding the attitude-behavior gap in social impact as- } \\
\text { sessment practice }\end{array}$ & Grieco & $\begin{array}{l}\text { Nonprofit Management } \\
\text { and Leadership }\end{array}$ & 2018 \\
\hline Analysing stakeholders' perceptions of golf-course-based & Dominguez-Gomez; & Tourism Management & 2017 \\
\hline
\end{tabular}




\begin{tabular}{|c|c|c|c|}
\hline $\begin{array}{l}\text { tourism: a proposal for developing sustainable tourism pro- } \\
\text { jects }\end{array}$ & Gonzalez-Gomez & & \\
\hline $\begin{array}{l}\text { Combined economic and social impact assessment of afforda- } \\
\text { ble housing investments }\end{array}$ & $\begin{array}{l}\text { Kunttu; Raikkonen; } \\
\text { Uusitalo; Forss; Ta- } \\
\text { kala; Tilabi } \\
\end{array}$ & $\begin{array}{l}\text { RISUS - Journal on In- } \\
\text { novation and Sustaina- } \\
\text { bility }\end{array}$ & 2017 \\
\hline Learning lessons from local social/poverty impact assessment & Mcinerney & Administration & 2017 \\
\hline $\begin{array}{l}\text { Sustainable infrastructure development challenges through } \\
\text { ppp procurement process indian perspective }\end{array}$ & $\begin{array}{l}\text { Agarchand; } \\
\text { Laishram }\end{array}$ & $\begin{array}{l}\text { International Journal of } \\
\text { Managing Projects in } \\
\text { Business } \\
\end{array}$ & 2017 \\
\hline $\begin{array}{l}\text { How the public reacts to social impacts in construction pro- } \\
\text { jects? A structural equation modeling study }\end{array}$ & $\begin{array}{l}\text { Wang; Han; De Vries; } \\
\text { Zuo }\end{array}$ & $\begin{array}{l}\text { International Journal of } \\
\text { Project Management }\end{array}$ & 2016 \\
\hline $\begin{array}{l}\text { Urban environmental assessment and social impact assess- } \\
\text { ment of tourism development policy: thailand's ayutthaya his- } \\
\text { torical park }\end{array}$ & Thanvisitthpon & $\begin{array}{l}\text { Tourism Management } \\
\text { Perspectives }\end{array}$ & 2016 \\
\hline $\begin{array}{l}\text { Perspectives on social impact measurement and non-profit or- } \\
\text { ganisations }\end{array}$ & $\begin{array}{l}\text { Polonsky; Grau; } \\
\text { Mcdonald }\end{array}$ & $\begin{array}{l}\text { Marketing Intelligence } \\
\text { \& Planning } \\
\end{array}$ & 2016 \\
\hline $\begin{array}{l}\text { Towards a social impact assessment of security technologies: a } \\
\text { bottom-up approach }\end{array}$ & $\begin{array}{l}\text { Hempel; Ostermeier; } \\
\text { Schaaf; Vedder }\end{array}$ & \begin{tabular}{|l} 
Science and Public Po- \\
licy
\end{tabular} & 2013 \\
\hline $\begin{array}{l}\text { Introducing a model for social impact assessment of public ad- } \\
\text { ministration reform in romania }\end{array}$ & Antonie & $\begin{array}{l}\text { Transylvanian Review } \\
\text { of Administrative Sci- } \\
\text { ences }\end{array}$ & 2012 \\
\hline Social impact assessment models & Antonie & $\begin{array}{l}\text { Transylvanian Review } \\
\text { of Administrative Sci- } \\
\text { ences }\end{array}$ & 2010 \\
\hline $\begin{array}{l}\text { Innovations in meta-analysis and social impact analysis rele- } \\
\text { vant for tech mining }\end{array}$ & Becker; Sanders & $\begin{array}{l}\text { Technological Forecast- } \\
\text { ing \& Social Change }\end{array}$ & 2006 \\
\hline Social impact assessment & Becker & $\begin{array}{l}\text { European Journal of } \\
\text { Operational Research }\end{array}$ & 2001 \\
\hline $\begin{array}{l}\text { Employment predictions in social impact assessment - an anal- } \\
\text { ysis of some unexplored variables }\end{array}$ & Lovejoy & $\begin{array}{l}\begin{array}{l}\text { Socio-Economic Plan- } \\
\text { ning Sciences }\end{array} \\
\end{array}$ & 1983 \\
\hline $\begin{array}{l}\text { A social impact assessment of the nuclear-fuel services facility } \\
\text { at west-valley, new-york }\end{array}$ & $\begin{array}{l}\begin{array}{l}\text { Milbrath; Kamie- } \\
\text { niecki }\end{array} \\
\end{array}$ & \begin{tabular}{|l|} 
International Journal of \\
Public Administration \\
\end{tabular} & 1982 \\
\hline $\begin{array}{l}\text { Social impact assessment of regional plans - a review of } \\
\text { methods and issues and a recommended process }\end{array}$ & $\begin{array}{l}\text { Cramer; Dietz ; Johns- } \\
\text { ton }\end{array}$ & Policy Sciences & 1980 \\
\hline
\end{tabular}

Fonte: Os autores (2020).

Desses 19 artigos analisados, também foi verificado quais eram os países com maior número de publicações e quais eram os países com maior número de citações. Assim como na análise geral das áreas do tema avaliação do impacto social, na área de Administração e Negócios, prevalece o domínio de países desenvolvidos, o que também é demonstrado pela Tabela 8, que contempla os cinco países com maior produção científica e os cinco países mais citados.

Tabela 8 - Países com maior produção e mais citações

\begin{tabular}{lc|lc}
\hline \multicolumn{1}{c|}{ Produção científica por país } & \multicolumn{2}{c}{ Países mais citados } \\
\hline País & $\begin{array}{c}\text { Número de } \\
\text { Artigos }\end{array}$ & País & $\begin{array}{c}\text { Número de Arti- } \\
\text { gos }\end{array}$ \\
\hline Austrália & 4 & Holanda & 69 \\
China & 4 & Austrália & 26 \\
Holanda & 4 & USA & 13 \\
Finlândia & 3 & Índia & 11 \\
Romênia & 2 & Alemanha & 7 \\
\hline
\end{tabular}

Fonte: Os autores (2020).

Nota-se também que os estudos da área de Administração e Negócios importam uma quantia considerável de conteúdo presente em estudos desenvolvidos em países do eixo europeu, com destaque para a Holanda, com 69 citações. Isso, é claro, está relacionado ao fato de que a Holanda aparece como 
o país com maior número de trabalhos publicados na área geral, contemplando os dois autores com maior número de publicações.

Para se verificar com quem os autores desses 19 artigos da área de Administração e Negócios colaboraram, podendo assim se averiguar o relacionamento da base intelectual do campo, foi gerado um mapa de cocitação dos trabalhos mais citados no software VOSViewer. 0 mapa é apresentado na Figura 3 , na qual é possível se identificar três clusters.

Tais clusters, sendo eles o vermelho, na parte inferior à esquerda, o verde na parte superior, e o azul na parte inferior direita, foram criados automaticamente pelo algoritmo do software VOSviewer, com base em características dos estudos.

Nesse mapa, a relação entre dois itens é ilustrada pela distância entre eles por meio de uma escala multidimensional. Logo, distâncias menores refletem relações mais próximas dentre os componentes do artigo (autores, referências e palavras-chave). Além disso, a amplitude do item apresenta a quantidade de citações que o trabalho recebeu em citações de outras publicações. Logo, quanto maior o número de citações de um trabalho, maior será o seu tamanho no mapa. Para complementar a análise da figura 3, são expostos, na tabela 9, os documentos pertencentes a cada um dos clusters.

Figura 3 - Análise de cocitação dos artigos por referência

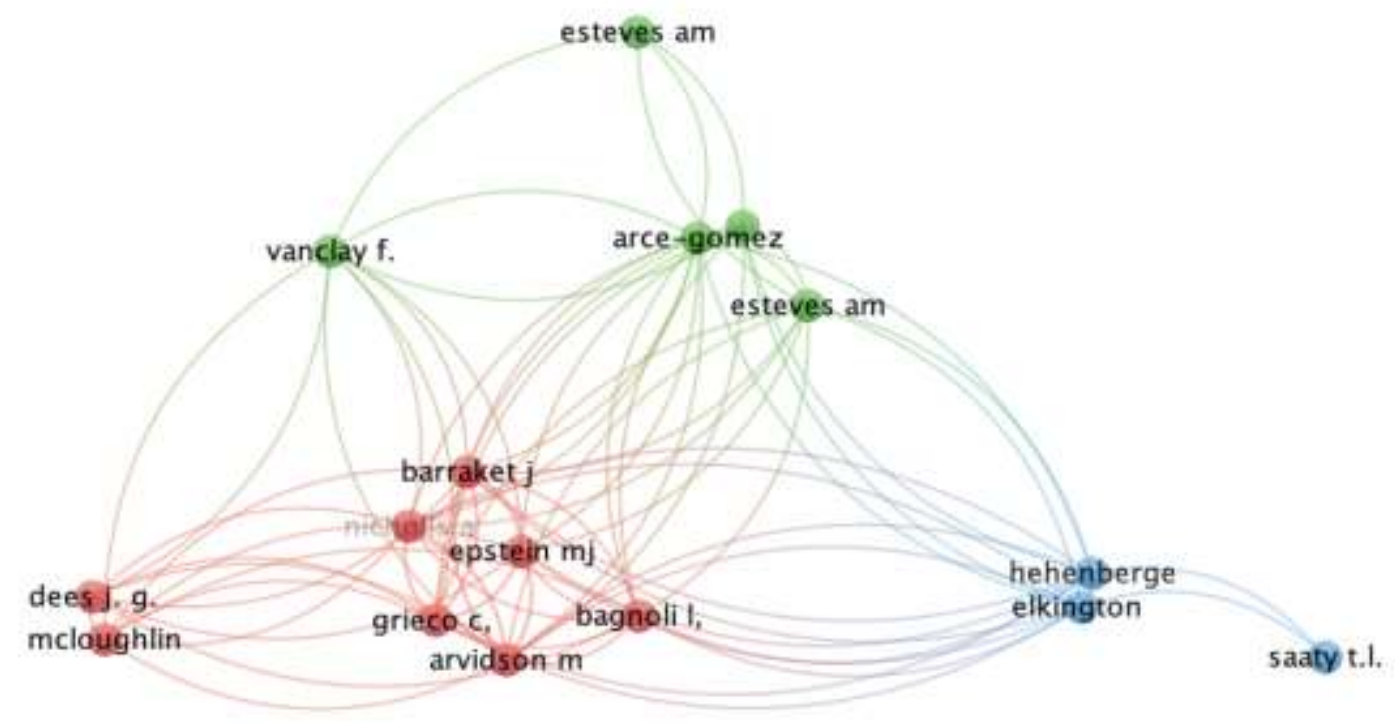

\begin{tabular}{cccccc}
\hline $\begin{array}{c}\text { Tipo de } \\
\text { Traba- } \\
\text { lho }\end{array}$ & $\begin{array}{c}\text { Tipo de } \\
\text { Análise }\end{array}$ & $\begin{array}{c}\text { Unidade } \\
\text { de Aná- } \\
\text { lise }\end{array}$ & $\begin{array}{c}\text { Número de Cita- } \\
\text { ções Mínimas }\end{array}$ & $\begin{array}{c}\text { Número de referên- } \\
\text { cias selecionadas }\end{array}$ & $\begin{array}{c}\text { Método de Norma- } \\
\text { lização }\end{array}$ \\
\hline AR & Co-citation & $\begin{array}{c}\text { Referên- } \\
\text { cias }\end{array}$ & 2 & 16 & Força da Associação \\
\hline
\end{tabular}

Fonte: Os autores (2020).

Para se averiguar como o software dividiu as referências em cada um dos três clusters, os trabalhos contidos na tabela 9 também foram lidos e avaliados de acordo com suas principais características. Após a análise, foi identificado que o cluster vermelho condensa os artigos que possuem como tema a mensuração dos impactos sociais, como o estudo de Arvidson, Lyon, McKay e Moro (2010) que avaliou os desafios de estudar o retorno dos investimentos em negócios sociais. No cluster verde, a temática dos assuntos está concentrada na avaliação do impacto social, ao passo que, no grupo azul, concentra os estudos seminais citados pelos 19 artigos que compõem a amostra de pesquisas aqui analisada.

Tabela 9- Documentos mais citados nos três clusters

\begin{tabular}{|c|c|c|c|c|}
\hline Cluster & Ano & Autores & Títulos & Local de Publicação \\
\hline$\stackrel{\varrho}{\rightleftarrows}$ & 2010 & $\begin{array}{l}\text { Arvidson, M., Lyon, F., McKay, S., \& } \\
\text { Moro, D. }\end{array}$ & The ambitions and challenges of SROI. & TSRC working paper 49 \\
\hline 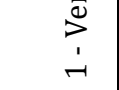 & 2011 & Bagnoli, L., \& Megali, C. & $\begin{array}{l}\text { Measuring performance in social enter- } \\
\text { prises. }\end{array}$ & $\begin{array}{l}\text { Nonprofit and Voluntary } \\
\text { Sector Quarterly }\end{array}$ \\
\hline
\end{tabular}




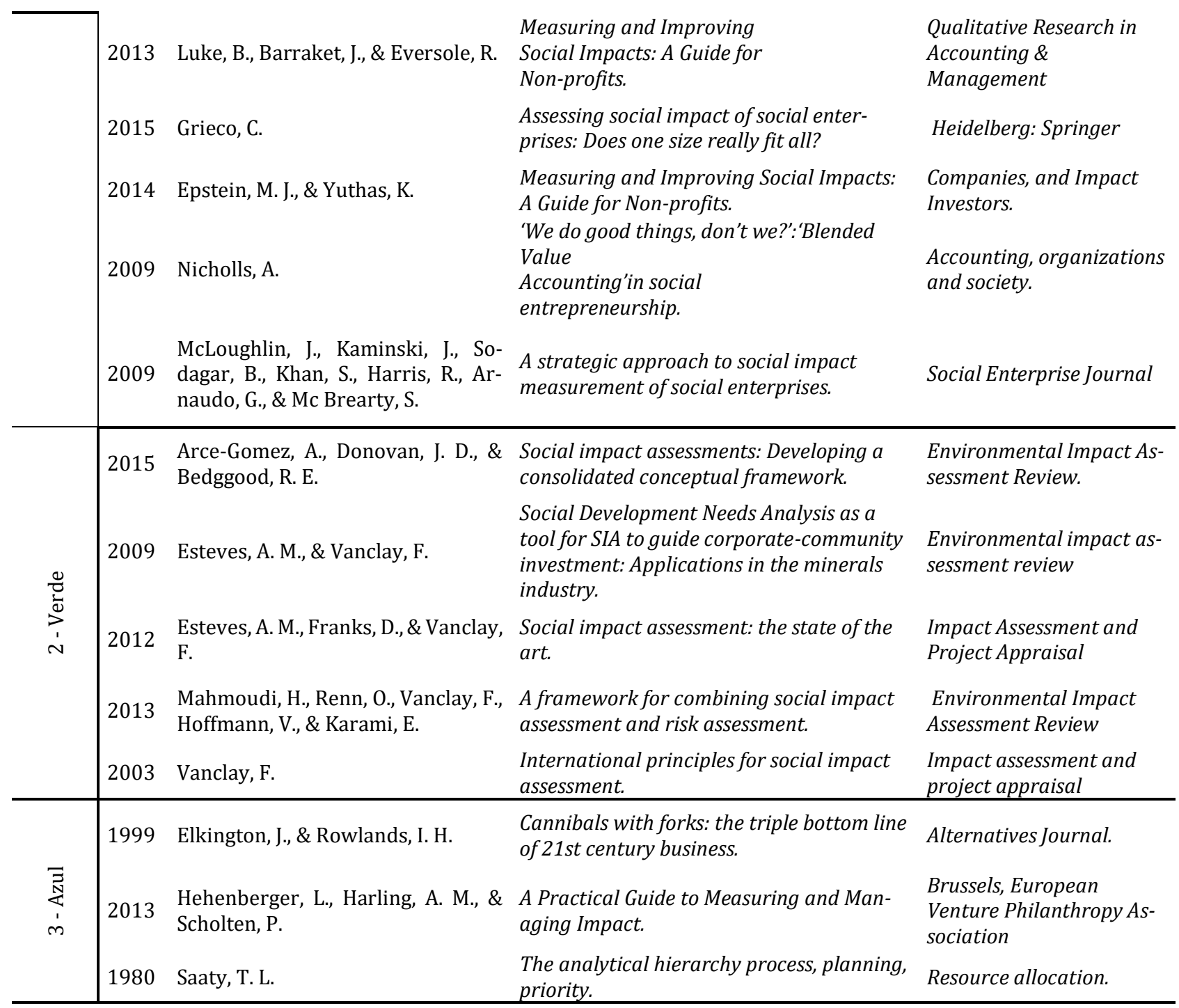

Fonte: Os autores (2020).

Percebe-se que além do que foi apresentado no cluster azul, as referências dos 19 trabalhos analisados na área de Administração e Negócios concentram-se em dois temas, Mensuração do Impacto Social e Avaliação do Impacto social, com destaque para o primeiro, que concentra meio número de referências.

Por fim, foi identificado quais dos 19 artigos tiveram maior número de citações em toda a base da Web of Science. Tais dados estão sumarizados na Tabela 10, na qual, novamente, se observa que os trabalhos mais citados estão concentrados em periódicos europeus e, principalmente, do Reino Unido. Tabela 10 - Documentos mais citados na área da Administração e Negócios

\begin{tabular}{lc}
\hline ARTIGOS MAIS CITADOS - ADMINISTRAÇÃO E NEGÓCIOS & Número de Citações \\
\hline $\begin{array}{l}\text { Becker, H. A. (2001). Social impact assessment. European Journal of Operational } \\
\text { Research, 128(2), 311-321. }\end{array}$ & 60 \\
Wang, Y., Han, Q., De Vries, B., \& Zuo, J. (2016). How the public reacts to social impacts in \\
$\begin{array}{l}\text { construction projects? A structural equation modeling study. International Journal of Project } \\
\text { Management, 34(8), 1433-1448. }\end{array}$ & 17 \\
$\begin{array}{l}\text { Agarchand, N., \& Laishram, B. (2017). Sustainable infrastructure development challenges } \\
\text { through PPP procurement process. International Journal of Managing Projects in Business. }\end{array}$ & 11 \\
$\begin{array}{l}\text { Cramer, J. C., Dietz, T., \& Johnston, R. A. (1980). Social impact assessment of regional plans: a re- } \\
\text { view of methods and issues and a recommended process. Policy Sciences, 12(1), 61-82. }\end{array}$ & 10 \\
$\begin{array}{l}\text { Polonsky, M. J., Grau, S. L., \& McDonald, S. (2016). Perspectives on social impact measurement } \\
\text { and non-profit organisations. Marketing Intelligence \& Planning. }\end{array}$ & 9 \\
\hline
\end{tabular}


Ao se comparar a Tabela 10 (área de Administração e Negócios) com a Tabela 5 (área geral), notamos que apesar de possuir apenas 19 artigos, os artigos da tabela 7 contabilizam cerca de $8 \%$ do total de referências citadas na Tabela 5. Porém, isso se deve ao fato de o artigo mais citado possuir 60 citações.

Com base nos dados apresentados nesta seção, são discutidas, na seção seguinte, as implicações teóricas e práticas do trabalho.

\section{Implicação teórica e prática}

Foi evidenciado que, tanto na análise bibliométrica referente à área geral do tema avaliação do impacto social quanto na análise sistemática da área de Administração e Negócios, existe uma predominância do eixo América do Norte e Europa no campo acadêmico. Tal situação resulta em um cenário onde estudos que abordem especificamente países ainda em desenvolvimento podem, em um primeiro momento, ser deixados de lado. Apesar de existirem várias pesquisas desenvolvidas pelos países referência no tema, como a Holanda, a ótica de pesquisadores residentes em países ainda em desenvolvimento pode prover novas possibilidades e contribuir com o avanço do campo, trazendo para ele visões e perspectivas diferentes.

Especificamente dentro da área de Administração e Negócios, ao se realizar uma análise dos países com maior foco nos estudos que buscaram metodologias ou melhores formas de mensurar o impacto social de forma aplicada à realidade, verifica-se que apesar de existir uma variação na localização global dos países e no seu grau de desenvolvimento, inexistem estudos dentro da área de Administração que trabalhem com países latino-americanos ou do continente africano, por exemplo. Em realidade, apesar de 15 dos 19 estudos analisados procurarem explorar a mensuração do impacto de forma aplicada, o número ainda é pequeno frente às possibilidades de pesquisa no campo. Estados Unidos e China são os dois únicos países em que mais de um estudo na área de Administração e Negócios foi desenvolvido para se avaliar o impacto social, como demonstrado no Tabela 11.

0 que os poucos estudos da área de Administração e Negócios apontam é que seria interessante existir uma maior regulamentação por parte do governo, além de um maior comprometimento desse com a causa da avaliação do impacto social (Agarchand \& Laishram, 2017; Hadad \& Gauca, 2014; Mcinerney, 2017), para auxiliar a avaliação com base nos contextos de cada um dos locais. Pois, como demonstrado por Chávez e Valenzuela (2019), em uma análise sobre a regulamentação da avaliação do impacto social já obrigatória para projetos energéticos no México, não houve uma adaptação adequada ao contexto local dos instrumentos de medição internacionais.

Tabela 11- Autores e seus respectivos campos de análises

\begin{tabular}{|l|l|l|}
\hline Citações & Campo de análise & País foco \\
\hline Agarchand e Laishram (2017) & Parcerias público-privadas & Índia \\
\hline Antonie (2010; 2012) & Reforma na administração pública & Romênia \\
\hline Chávez e Valenzuela (2019) & Projetos de energia de pequena escala & México \\
\hline Dominguez-Gómez e Gonzalez-Gómez (2017) & Resort de golf & Espanha \\
\hline Grieco (2018) & Empresas sociais & Itália \\
\hline Hempel et al. (2013) & Tecnologias de segurança & Não se aplica \\
\hline Hervieux e Voltan (2019) & Empreendimentos sociais & EUA e Canadá \\
\hline Kunttu et al. (2017) & Habitações acessíveis & Não se aplica \\
\hline Leung et al. (2019) & Empresas sociais de integração de trabalho & China \\
\hline Lovejoy (1983) & Empreendimentos energéticos & Não se aplica \\
\hline McInerney (2017) & Formulação de políticas locais & Irlanda \\
\hline Milbrath e Kamieniecki (1982) & Serviços de combustível nuclear & EUA \\
\hline Polonsky, Grau e McDonald (2016) & Organizações sem fins lucrativos & EUA e Austrália \\
\hline Thanvisitthpon (2016) & Parque histórico & Tailândia \\
\hline Wang et al. (2016) & Rodovia & China \\
\hline
\end{tabular}

Fonte: Os autores (2020).

Isso remete a uma questão importante que diz respeito ao contexto das pesquisas, e, como já 
mencionado, à realidade na qual o pesquisador se encontra. Como apontado por Antonie (2012), Chávez \& Valenzuela (2019) e Mcinerney (2017), deve-se sempre levar em conta os diferentes contextos de cada tipo de organização e os diferentes stakeholders envolvidos (Hadad \& Gauca, 2014; Hempel et al., 2013), podendo, inclusive, ocorrer o desenvolvimento de diferentes formas de relatórios, para atender os diferentes tipos de atores interessados (Becker, 2001).

Esse envolvimento de diferentes stakeholders, desde a elaboração até o recebimento das informações, foi destacado por diversos autores, sendo inclusive o aspecto de maior concordância entre eles (Chávez \& Valenzuela, 2019; Hempel et al., 2013; Kunttu, 2017; Mcinerney, 2017; Polonsky et al., 2016). Como apontado por Agarchand e Laishram (2017), são os funcionários de uma organização ou membros de uma comunidade que vivenciam as suas rotinas, seus desafios e os impactos gerados, entendendo melhor o que é relevante para a medição.

Nesse sentido, é necessário que artigos da área de Administração e Negócios atentem para o fato de que não se pode simplesmente importar um instrumento de medição para dentro de um contexto, sendo necessário uma profunda compreensão do cenário de impacto social que se pretende medir. Considerando que tanto a área geral como a área específica de Administração e Negócios apresentam uma predominância do eixo Norte Americano e Europeu nos trabalhos acadêmicos, a avaliação do impacto social em países que fujam desse contexto pode se tornar comprometida, principalmente, ao se observar que países menos desenvolvidos, donde a mensuração do impacto social é de extrema importância, parecem ficar de fora, pelo menos para os estudos analisados nessa amostra.

Como mencionado por Chávez e Valenzuela (2019), muitos subestimam a grandeza de informações que podem ser coletadas por meio do diálogo com a comunidade, principalmente, em projetos de pequena escala, como o entendimento sobre o público atingido, aspecto que medidas quantitativas não conseguiriam captar. Isso é algo que Cramer, Dietz e Johnston (1980) já argumentavam quando afirmavam que alguns impactos precisam ser identificados qualitativamente, por meio de conversas com especialistas ou com a própria população.

Nesse sentido, é importante que os estudos de avaliação do impacto social atentem para o fato de que, apesar da existente literatura, essa se concentra em um eixo e parece ser aplicada a países que possuem contextos distintos, exigindo do pesquisador uma acurácia e certo cuidado ao se basear em tais estudos e, principalmente, em modelos prontos, para se tentar avaliar ou mensurar o impacto social. Isto é valido para organizações que pretendem avaliar, de forma prática, o impacto social causado. Treinamentos, algo que Grieco (2018) e Mcinerney (2017) apontam como necessários para gestores e funcionários desenvolverem as capacidades e habilidades necessárias para a elaboração, efetuação e análise da avaliação do impacto social, devem ser realizados levando em conta o contexto no qual a organização se encontra inserida, sob o risco de se acabar avaliando algo completamente fora de contexto. Polonsky et al. (2016) apontam que para aumentar sua eficácia e ser independente operacionalmente ao realizar suas avaliações, esses treinamentos organizacionais são importantes. Esse estudo indica que em conjunto com isso, deve-se levar em conta os aspectos contextuais também para os treinamentos organizacionais.

\section{Considerações finais}

Utilizando uma análise bibliométrica do campo geral em conjunto com uma revisão sistemática dos artigos da área de Administração e Negócios, este estudo teve como objetivo compreender o panorama científico do tema avaliação do impacto social.

Com tal abordagem, evidenciou-se que apesar do desenvolvimento da área geral do tema, principalmente entre os anos de 2013 e 2019, contabilizando cerca de $61 \%$ da amostra, a base das pesquisas se encontra na maior parte concentrada nas áreas dos estudos ambientais. Tal cenário se reflete nos estudos da área de Administração e Negócios, demonstrando que apesar de existir um desenvolvimento, esse cenário ainda se caracteriza por uma importação de conteúdo da área ambiental, o que sugere que o campo de avaliação do impacto social ainda não atingiu sua maturidade. 0 fato de existir apenas 20 estudos na área de Administração e Negócios é outro indicativo disso, ainda sendo difuso o entendimento da mensuração e avaliação do impacto social nessa área.

Nota-se também que a University of Groningen, na Holanda, é o atual centro de pesquisas sobre o tema, tendo dois dos autores que mais publicaram artigos filiados a ela. Logo, acompanhar publicações e eventos promovidos por essa universidade pode ser interessante aos pesquisadores que possuem interessem em publicar no tema. 
Porém, e como já mencionado, é necessário que o campo se desenvolva com publicações que analisem diferentes contextos em diferentes países, pois uma grande dificuldade exposta pela revisão sistemática é a questão "como se mensurar o impacto?", o que envolve diretamente o contexto que se pretende analisar.

O baixo número de artigos relacionados à avaliação do impacto social na área de Administração e Negócios pode estar também relacionado ao fato de que ainda inexiste uma extensa literatura na área de impacto social que trabalhe, especificamente, com a mensuração desse impacto, o que compromete a análise da avaliação do impacto. Isso ocorre porque, de acordo com os dados do mapa da Figura 3, a mensuração social é a principal fonte de referência para os 19 artigos de Administração e Negócios que trabalharam com a avaliação do impacto social.

Nesse sentido, estudos futuros precisam melhor explorar os aspectos relacionados à mensuração do impacto social. E ao fazer isso, devem atentar para não fugir da realidade que se pretende analisar, pois apesar do fato de não existir uma forma padronizada para efetuar essa avaliação (Grieco, 2018; Polonsky et al., 2016), uma análise profunda sobre quem são os beneficiários diretos e indiretos, entendendo suas características sociais, culturais e econômicas (Antonie, 2010) e adaptando o instrumento à realidade do projeto (Chávez \& Valenzuela, 2019), pode, com certeza, contribuir para um melhor entendimento do impacto social. Assim, é perceptível que para as metodologias e instrumentos se adequarem à realidade do campo, os pesquisadores precisam se aprofundar nas suas características.

Como apontado por Cramer, Dietz e Johnston (1980), os diferentes impactos sociais não deveriam nem ser comparados em números brutos, apenas em magnitude, dependendo do caso, o que faz com que uma metodologia universal ou padrão não seja cogitada para ser apenas importada. Logo, estudos futuros devem ter cuidados adequados com o contexto, contendo mais ideias e opções a serem empregadas do que um passo a passo rígido.

A temática de avaliação do impacto social ainda se apresenta como incipiente no mundo acadêmico e apesar desse estudo ter utilizado apenas uma base de dados para sua análise e o conjunto de dois métodos, sendo um bibliométrico e um sistemático, contribui para evidenciar essa incipiência.

Nesse sentido, seria interessante que estudos futuros bibliométricos e sistemáticos utilizassem diferentes bases de dados, em especial comparando os achados do presente estudo a potenciais resultados obtidos em bases de dados diferentes. Resultados comparativos com diferentes bases de dados podem demonstrar novas perspectivas e, assim, contribuir ainda mais para o desenvolvimento do campo.

\section{Agradecimentos}

Este estudo foi financiado em parte pela Coordenação de Aperfeiçoamento de Pessoal de Nível Superior - Brasil (CAPES) - Código Financeiro 001.

\section{Referências}

Agarchand, N., \& Laishram, B. (2017). Sustainable infrastructure development challenges through PPP procurement process. International Journal of Managing Projects in Business, 10(3), 642-662. https://doi.org/10.1108/IJMPB-10-2016-0078

Antonie, G. (2010). Social impact assessment models. Transylvanian Review of Administrative Sciences, 29 E, 22-29.

Antonie, R. (2012). Introducing A Model For Social Impact Assessment Of Public Administration Reform In Romania. Transylvanian Review of Administrative Sciences, 36, 5-12.

Arvidson, Malin, Lyon, Fergus, McKay, Stephen and Moro, Domenico (2010) The ambitions and challenges of SROI. Working Paper. TSRC, Birmingham.

Becker, H. A. (2001). Social impact assessment. European Journal of Operational Research, 128(1), 311321. https://doi.org/10.1080/07349165.1984.9725505

Cassundé, F. R., Barbosa, M. A. C., \& Mendonça, J. C. de. (2016). Terceirização e Precarização do Trabalho: Levantamento Bibliométrico sobre os Caminhos Críticos da Produção Acadêmica em Administração. Teoria e Prática Em Administração (TPA), 6(1), 176-197. https://doi.org/10.21714/tpa.v6i1.28019

Chávez, B. V., \& Valenzuela, M. B. (2019). La medición a pequeña escala de los impactos sociales de proyectos de energía: Problemas metodológicos e implicaciones de política. Gestión y Política Pública, 28(2), 377-406. https://doi.org/10.29265/gypp.v28i2.624

Cramer, J. C., Dietz, T., \& Johnston, R. A. (1980). Social impact assessment of regional plans: a review of 
methods and issues and a recommended process. Policy Sciences, 12(1), 61-82. https://doi.org/10.1007/BF00137363

Esteves, Ana Maria; Franks, Daniel; Vanclay, Frank. (2012). Social impact assessment: the state of the art. : the state of the art. Impact Assessment And Project Appraisal, [s.l.], 30 (1) p. 34-42. Informa UK Limited. http://dx.doi.org/10.1080/14615517.2012.660356.

Greider, Thomas; Garkovich, Lorraine. (1994). Landscapes: the social construction of nature and the environment. : The Social Construction of Nature and the Environment. Rural Sociology, [s.l.], 59 (1), p. $1-24$.

Grieco, C. (2018). What do social entrepreneurs need to walk their talk? Understanding the attitude behavior gap in social impact assessment practice. Nonprofit Management and Leadership, 29(February), 105-122. https://doi.org/10.1002/nml.21310

Hadad, S., \& Gauca, O. (2014). Social impact measurement in social entrepreneurial organizations. Management \& Marketing, 9(2), 119-136.

Hempel, L., Ostermeier, L., Schaaf, T., \& Vedder, D. (2013). Towards a social impact assessment of security technologies: A bottom-up approach. Science and Public Policy, 40, 740-754. https://doi.org/10.1093/scipol/sct086

Hervieux, C., \& Voltan, A. (2019). Toward a systems approach to social impact assessment. Social Enterprise Journal, 15(2), 264-286. https://doi.org/10.1108/SEJ-09-2018-0060

Internacional Association For Impact Assessment (IAIA) (2020). (Estados Unidos). Impact assessment: The leading global network on impact assessment. Disponível em: <https://www.iaia.org/>. Acesso em: 29 jan. 2020.

Kunttu, A. (2017). Combined economic and social impact assessment of affordable housing investments . RISUS - Journal on Innovation and Sustainability, 8, 85-93.

Liberati, A., Altman, D. G., Tetzlaff, J., Mulrow, C., Gøtzsche, P. C., Ioannidis, J. P. A., Moher, D. (2009). The PRISMA statement for reporting systematic reviews and metaanalyses of studies that evaluate health care interventions: Explanation and elaboration. Annals of Internal Medicine, 151, W-65. https://doi.org/10.7326/0003- 4819-151-4-200908180-00136.

Leung, Z. C. S., Ho, A. P. Y., Tjia, L. Y. N., Tam, R. K. Y., Chan, K. T., \& Lai, M. K. W. (2019). Social Impacts of Work Integration Social Enterprise in Hong Kong-Workfare and Beyond. Journal of Social Entrepreneurship, 10(2), 159-176. https://doi.org/10.1080/19420676.2018.1541007

Lovejoy, S. B. (1983). EMPLOYMENT PREDICTIONS IN SOCIAL IMPACT ASSESSMENT : AN ANALYSIS OF SOME UNEXPLORED VARIABLESt. Socio-Economic Planning Sciences, 17(2), 87-93.

Mcinerney, C. (2017). Learning lessons from local social / poverty impact assessment. Administration, 65(3), 41-58. https://doi.org/10.1515/admin-2017-0023

Milbrath, L. W., Kamieniecki, S., \& Angeles, L. (1982). A social impact assessment of the nuclear fuel services facility at west valley, New York. International Journal of Public Administration, 4(2), 113-134. https://doi.org/10.1080/01900698208524428

Osareh, F. (1996). Bibliometrics, Citation Analysis and Co-Citation Analysis: Libri, 46, 149-158.

Polonsky, M. J., Grau, S. L., \& McDonald, S. (2016). Perspectives on social impact measurement and nonprofit organisations. Marketing Intelligence \& Planning, 34(1), 80-98. https://doi.org/10.1108/MIP$\underline{11-2014-0221}$

Rocha, D. T.; Cruz, J. A. W.; Azevedo, M. B.; Ancrich, R. G.; Tardelli, M.; Abdalla, K. G. M. Z. (2014) Finanças: Um Estudo Bibliométrico e Sociométrico da Produção Científica Brasileira. Revista Pensar Contábil, 16 $(60)$.

Snyder, H. (2019). Literature review as a research methodology: An overview and guideliness. Journal of Business Research 104, 333-339. https://doi.org/10.1016/j.jbusres.2019.07.039

Thanvisitthpon, N. (2016). Urban environmental assessment and social impact assessment of tourism development policy: Thailand's Ayutthaya Historical Park. Tourism Management Perspectives, 18. 1-5.

Van Eck, N. J., Waltman, L. (2010). Software survey: VOSviewer, a computer program for bibliometric mapping. Scientometrics, 84(2), 523-538.

Villas Boas, A.; Serrato, A. C.; Zdziarski, A. D. Cruz, J. A. W. (2019). Mapeamento das temáticas dos dossiês das revistas dos programas de pós-graduação em Ciências da Religião e Teologia no Brasil. Revista de Estudos da Religião, 19 (2).

Wang, Y., Han, Q., Bauke de Vries, Zuo, J. (2016). How the public reacts to social impacts in construction projects? A structural equation modeling study. International Journal of Project Management 34. 1433- 
1448.

Zupic, I., \& Čater, T. (2015). Bibliometric Methods in Management and Organization. Organizational Research Methods, 18(3), 429-472. https://doi.org/10.1177/1094428114562629 